\title{
Ground motion and air overpressure study
}

\author{
Michael K. Sharp and Donald E. Yule \\ Geotechnical Laboratory, Earthquake Engineering \\ and Geosciences Division, USAE Waterways \\ Experiment Station, 3909 Halls Ferry Road, \\ Vicksburg, MS 39180-6199, USA \\ Tel.: +16016343787
}

Received 15 March 1997

Revised 13 July 1998

A seismic attenuation and air overpressure study was conducted to determine the attenuation of explosion induced ground motions and air overpressures as a function of distance from shallow subsurface detonated charges, and to derive parameters to predict blast effects at distances beyond the ordinance disposal facility boundary. A total of 210 explosive shots were monitored producing 2048 time histories of ground motions recorded in the vertical, radial, and transverse directions, in addition to recording air overpressures. The data were analyzed for peak particle velocities and peak air overpressures, then plotted versus scaled range. A best fit line was determined for the data to give average, 95\% nonexceedance, and upper bound predictive equations which can be used in the disposal operations to avoid damage to adjacent structures.

\section{Introduction}

The disposal of ordinance and other dangerous materials by explosive detonation provides many advantages, however, one concern that is always present is insuring that damage is avoided to nearby structures. This concern is addressed by setting conservative operational parameters, e.g., charge size, and permitting weather conditions, that will result in blast effects that pose no threat to these structures. The use of conservative parameters are important not only to avoid actual damage but reduce claims of perceived damage that result from public awareness of the blasting. The blasting community has empirical relations for generic prediction of blast effects, but a site-dependent study provides a sound and more defendable evidential basis to insure that safe blasting criteria are being met. This case history presents the method for collecting and pro- cessing the test data, and its application to safe limiting blast criteria.

This study was for a facility that has the responsibility for disposing of ammunition, explosives and other dangerous articles by detonation. This blasting activity is conducted at the demolition grounds of the facility where this material is detonated on a daily basis, as dictated by site conditions (weather, safety, etc.). The total amount of material disposed of each day is approximately 15,000 pounds, detonated in several pits each containing less than $500 \mathrm{lbs}$. The purpose of this study was twofold: (1) determine the attenuation of explosion induced ground motions and air overpressures as a function of distance from subsurface detonated charges; (2) develop procedures to predict ground particle velocities and air overpressures at distances beyond the base boundary. The development of these prediction procedures will then allow the facility to determine the blast effects as a function of explosive size (charge weight) at a given distance and using safe blasting criteria assess the potential for off-site structural damage or complaints.

\section{Regional geology and site description}

Measured ground motions may be simply described as the convolution of four effects: source, transmission path, recording site, and recording instrument response. Two of these components are functions of the transmitting medium's material properties which explains the importance in understanding the geology of the study area. The Indiana Department of Natural Resources prepared a report describing the stratigraphy of the study area [4], from which a discussion of the site geology is excerpted. The facility is located in the southeastern portion of the Illinois Basin, which is a large cratonic basin that began forming during Cambrian time. It is filled by a sequence of Paleozoic sediments, Mississippian and Pennsylvanian, of which the youngest preserved are of Pennsylvanian age (320 to $286 \mathrm{Ma}$ ). The Mississippian units exposed consist of interbedded shales, limestones and sandstones of the Blue River, West Baden, Stephensport, and Buffalo 


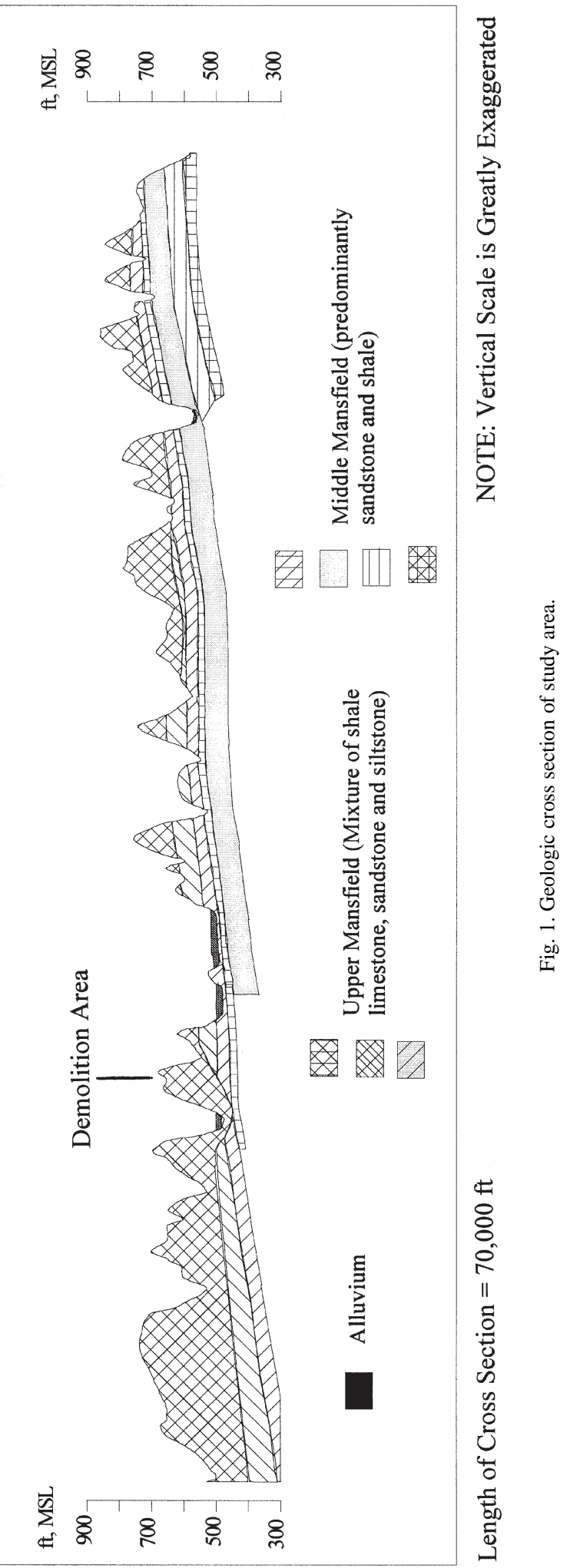




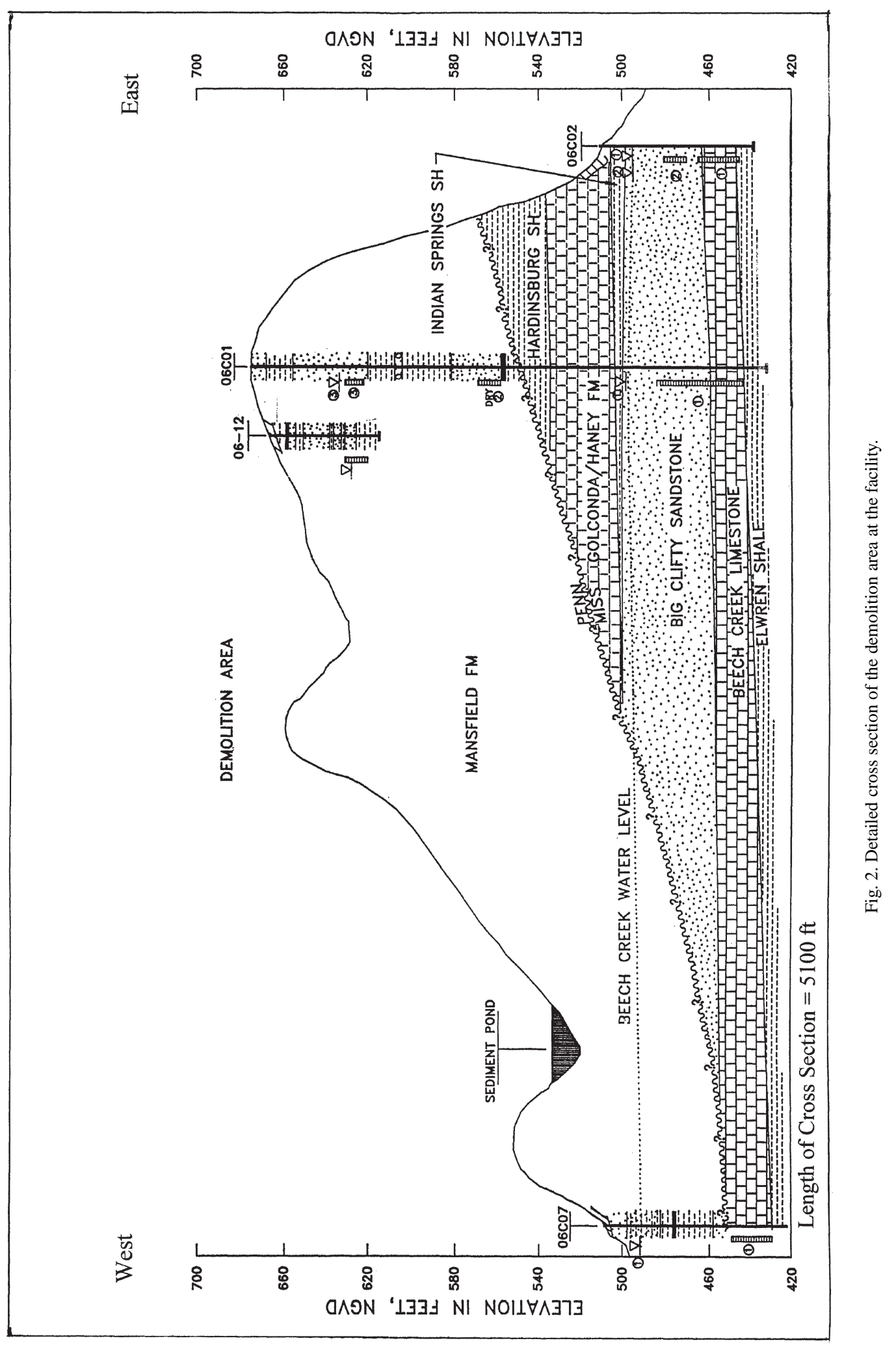


Wallow Groups. The Pennsylvanian section at Crane consists almost exclusively of interbedded sandstones, siltstones, shales, coals, and underclays of the Mansfield Formation.

Three regional cross sections were constructed based on 60 coreholes containing anywhere from 13 to $246 \mathrm{ft}$ of Pennsylvanian section. One of the cross sections representative of the facility is shown in Fig. 1. The overburden is shallow, ranging from approximately 10 to $20 \mathrm{ft}$. The remainder of the sections reveal intermittent layers of sandstones, siltstones, shales, and coal. Therefore, over the distances where ground motions were recorded (up to 22,000 ft) the waves will be traveling through the deeper competent rock layers. A detailed cross section for the demolition area was also constructed and shown in Fig. 2. This geologic section shows that the thickness of overburden overlying the Pennsylvanian rock ranges from zero to only a few feet.

The actual explosive demolition area encompasses approximately 17 acres (Fig. 3), with a $500 \mathrm{ft}$ radius cleared of grass and brush. The site is located on a ridge with the area where detonation occurs lying on the north and south slopes. Demolition can also be performed on the east slope of the ridge. The demolition occurs in pits that are aligned in rows on each slope of the ridge. The ridge has approximately $40 \mathrm{ft}$ of topographic variation.

\section{Blast source characteristics}

The demolition range disposes of many different types of ordinance material. In addition to the material being disposed of, each pit has some type of initiator to insure a complete explosion. For the period of this investigation, the primary material being disposed of consisted of high explosive fuzes, $106 \mathrm{~mm}$ shells, H- 6 bombs, $20 \mathrm{~mm}$ shells, 8 inch and 5 inch projectiles, and 5 inch propellant charges. The primary initiators were TNT, C3, C4, and H-6. The total charge size reported per pit is given as the net explosive weight (NEW), which is the sum of the explosive material being disposed of and the initiator. A more accurate way to express charge weight would be to convert the individual explosive weights for different components to a common basis such as TNT equivalence since many different types of explosive were disposed of at the site. However, detailed information about the type and amount of explosive in each shell or projectile was not available, and the conversion to TNT equivalence could not be performed. The pits are typically dug to a depth of 8-10 ft and backfilled 5-6 ft above the ground surface before detonation. Each pit is allowed a maximum quantity of $500 \mathrm{lbs}$ (NEW) of explosives.

\section{Test methodology}

Explosion generated ground shock waves can be divided into four main categories; compressive $(\mathrm{P})$, shear (S), surface, and air waves. These main wave types can be divided into two classes; body waves which propagate through the body of the rock and soil, and surface waves which are transmitted along a surface (usually the ground surface). Body waves are the $\mathrm{P}$ waves and the distortional $\mathrm{S}$ waves, while the most important surface waves are the Rayleigh (R) waves. Explosions produce predominantly body waves at small distances which propagate outward in a spherical manner until they intersect a boundary such as another rock layer, soil, or the ground surface. At boundaries body waves reflect, refract, convert (P to $\mathrm{S}$ or $\mathrm{S}$ to $\mathrm{P}$ ), and produce surface (boundary) waves. At larger transmission distances, the $\mathrm{R}$ waves become dominant. All three wave types arrive together at small distances but begin to separate at larger distances. To define the ground motion, three mutually perpendicular components are measured (vertical, radial, and transverse). No one of these components generally dominates in blasting, and the peak component varies with each blasting sequence. The most important parameters that describe the time history of particle motions are peak amplitude, principal period, and duration of the vibration. All these parameters are dependent on the explosive energy and the transmission medium.

Scaling of distance is necessary to predict peak particle velocities when both the charge weight $(W)$, and the distance or range $(R)$, vary. The two most common approaches are square root, $R / W^{1 / 2}$, scaling and cube root, $R / W^{1 / 3}$, scaling. Square root scaling, plotting peak particle velocity or air overpressure as a function of the distance divided by the square root of the charge weight, is used for far-field, Rayleigh wave dominated environments. For close-in measurements, regions where motions are dominated by $\mathrm{P}$ - or $\mathrm{S}$-waves, cube root scaling is used. Also, scaling relationships are the most accurate when they are derived from similar $W$ and $R$ values and not similar ratios of $R / W^{n}[2]$.

Air blasts or air pressure waves are reported in two different units of measurement, pressure (psi) or deci- 


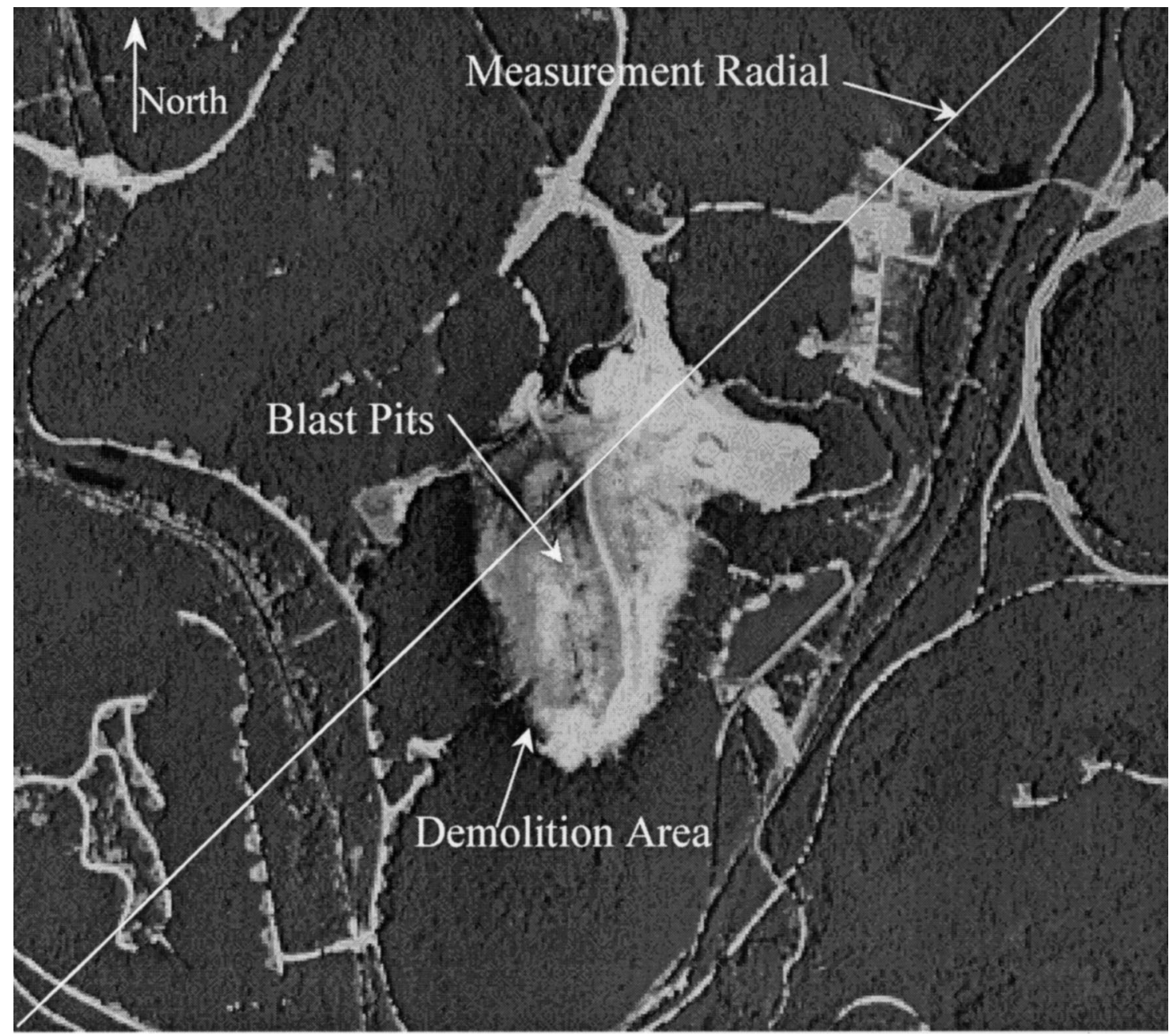

Fig. 3. Areal view of the demolition area, showing northeast and southwest measurement radial.

bels $(\mathrm{dB})$. When pressure units are reported they are often called overpressures to indicate that the measured pressure is that above atmospheric. Scaling of distance for peak air overpressure plots are usually evaluated only as a function of cube root scaling. The higherfrequency portion of the pressure wave is audible and is the sound that accompanies a blast; the lowerfrequency portion is not audible but excites structures and in turn causes a secondary and audible rattle within a structure. Air blasts are of interest for three reasons. First, by themselves or in combination with ground motions, they can produce structural motions that create structural cracks. Second, they can crack windows, although the air blast would have to be high (generally about 0.1 psi or $150 \mathrm{~dB}$ ). The third reason being that most humans have adverse reactions to loud noises, and perceive that damage is resulting.

\section{Instrumentation}

Each measurement station consisted of four data channels; three seismic monitoring channels and one air overpressure monitoring channel. The measurement stations were a triaxial array of calibrated sensitive geophones (velocity transducers) oriented to detect the vertical, radial, and transverse components of the ground motion and a calibrated microbarograph (air pressure transducer) to detect air overpressure. The microbarograph is composed of a pressure cell transducer and signal amplifier. The geophones have a natural frequency of $1.0 \mathrm{~Hz}$ and a range of sensitivities from 3.07-4.55 Volts/in/sec (V/ips). The microbarographs have a frequency response from 0 to $1000 \mathrm{~Hz}$ and a sensitivity of 10.0-45.0 Volts/lb/in ${ }^{2}$ (V/psi). 


\section{Test layout and procedure}

The actual test program consisted of recording data on consecutive days under varying blasting and weather conditions and along two separate radial lines. Each day's recording consisted of either four or five stations placed at varying distances from the blast source along radials have bearings $\mathrm{N} 40^{\circ} \mathrm{E}$ and $\mathrm{S} 40^{\circ} \mathrm{W}$. Table 1 contains information about the number of recording stations, locations for each days testing, and the pertinent weather information. Note that the locations in Table 1 are the distances between the recording stations and the closest blast source.

The geophones were buried flush with the ground surface to reduce the amount of cultural noise. The microbarographs were placed on a level stable surface $1 \mathrm{ft}$ above the ground surface.

\section{Blast safety criteria and analysis}

A final step in the analysis is to compare the recorded velocities and air overpressures obtained at the recording sites to established safe blast limiting criteria. Past studies have proven that ground recorded peak particle velocities are a good correlative variable to threshold damage of residential structures $[1,5]$. The two criteria used in this analysis are shown in Fig. 4. The distance dependent criteria was established for structures located between 300 and $5000 \mathrm{ft}$ from a blast by the U.S. Department of Interior Office of Surface Mines (OSM) Reclamation and Enforcement 30 CFR Part 715, effective April 7, 1992 [3]. These criteria allow for a PPV of 1.0 ips (allowable vibration limits) and PAO of 0.015 psi (allowable air blast limit). These criteria are based on open coal mine blasting which utilizes very large shots and many delays. Most of the energy of a coal mine blast is in the low frequency range of 5-25 Hz. Quarry blasting is in the range of $10-35 \mathrm{~Hz}$, and construction blasting in the range of 15-60 Hz. The safe limiting criteria are based on surface coal mine blasting because the lower frequency motions produce much more structural damage than do the higher frequency motions. The blasting that occurs at this facility is very similar to quarry or construction blasting which utilizes smaller shots and produces more high frequency motions. Therefore, the predictions of blast safety based on coal mine blasting criteria would provide additional conservatism for quarry or construction type blasting.
A second method to establish safe limiting criteria has also been developed by the Department of the Interior, OSM Reclamation and Enforcement. These rules and regulations are established in 30 CFR Parts $715,780,816$, and 817 [3]. The new alternative frequency dependent blasting criteria is based on the particle velocity (ips) versus the frequency $(\mathrm{Hz})$ as shown in Fig. 4. Once the time history from a ground vibration monitoring station has been recorded, the spectral content can be found by calculating power spectral densities (PSD) from which peak frequencies can be determined. These peak frequencies are used in Fig. 4 to determine safe particle velocities. The OSM further refined the distance based criteria establishing the following standard for peak particle velocities to prevent the occurrence of threshold damage; 1.25 ips for 0-300 ft from source, 1.0 ips for distances of 301 to $5,000 \mathrm{ft}$ from the source, and $0.75 \mathrm{ips}$ for $5,001 \mathrm{ft}$ and beyond from the source.

\section{Results and analysis}

The calibrated field data were recorded analog and unfiltered. Calculations were made to determine maximum peak particle velocities (PPV) and peak air overpressures (PAO) for each seismic and acoustic recorded time history. The blast monitoring program generated 2,048 time histories recorded in the study area. A representative time history is shown in Fig. 5. The maximum unfiltered peak particle velocity detected by each geophone at each station from each test was determined and plotted versus scaled range for both square and cube root scaling. These sets of data were then statistically analyzed using linear regression to determine the best fit ground motion attenuation relationships. These functions represent the average expected value predictions, and are based on a simplistic model (explosive weight and distance) and cannot account for the scatter of the actual multi-variable phenomina. The assumed mathematical model for this relationship is:

$$
\mathrm{PPV}=C_{1}\left(R / W^{C_{2}}\right)^{C_{3}},
$$

$C_{2}$ - scaling constant equal to $1 / 2$ or $1 / 3, R$ - distance from source in feet, $W$ - charge size in pounds, $C_{1}$ and $C_{3}$ - constants determined from regression analysis.

The set of air overpressure measurement data were also statistically analyzed using the same procedure as that for peak particle velocity. The air overpressures 
Table 1

Locations of recording stations and weather information

\begin{tabular}{|c|c|c|}
\hline $\begin{array}{l}\text { Recording date, radial and } \\
\text { number of discrete blasts }\end{array}$ & $\begin{array}{l}\text { Nominal station } \\
\text { locations, } \mathrm{ft}\end{array}$ & Weather information \\
\hline 28 August, $\mathrm{N} 40^{\circ} \mathrm{E}, 45$ blasts & $500,5800,10000$ & $\begin{array}{l}\text { Temp } 69^{\circ} \text {, humidity } 63 \% \text {, wind } \mathrm{N} 9 \mathrm{mph} \text {, partly } \\
\text { cloudy, barometer } 29.98 \text {, ceiling } 2500 \mathrm{ft}\end{array}$ \\
\hline 29 August, $N 40^{\circ} \mathrm{E}, 45$ blasts & $500,1000,5800$ & $\begin{array}{l}\text { Temp } 73^{\circ} \text {, humidity } 57 \% \text {, wind S } 9 \mathrm{mph} \text {, clear } \\
\text { barometer } 30.11 \text {, ceiling unlimited }\end{array}$ \\
\hline 31 August, $N 40^{\circ} \mathrm{E}, 30$ blasts & $\begin{array}{l}500,750,1000,1450, \\
5800\end{array}$ & $\begin{array}{l}\text { Temp } 71^{\circ} \text {, humidity } 57 \% \text {, wind W } 5 \mathrm{mph} \text {, } \\
\text { partly cloudy, barometer } 30.20^{\prime} \text { ceiling } 3000 \mathrm{ft}\end{array}$ \\
\hline 1 September, $\mathrm{S} 40^{\circ} \mathrm{W}, 45$ blasts & $\begin{array}{l}500,2900,5800 \\
10800,22000\end{array}$ & $\begin{array}{l}\text { Temp } 73^{\circ} \text {, humidity } 62 \% \text {, wind SE } 7 \mathrm{mph} \text {, } \\
\text { hazy, barometer } 30.20 \text {, ceiling } 5000 \mathrm{ft}\end{array}$ \\
\hline 3 September, $\mathrm{S} 40^{\circ} \mathrm{W}, 45$ blasts & $250,500,750,2900$ & $\begin{array}{l}\text { Temp } 77^{\circ} \text {, humidity } 74 \% \text {, wind W } 6 \mathrm{mph} \text {, } \\
\text { partly cloudy, barometer } 30.08 \text {, ceiling } 1500 \mathrm{ft}\end{array}$ \\
\hline
\end{tabular}

Blasting Level Criteria

(Distance Dependent, Frequency Content 5-25 Hz)
Alternative Blasting Level Criteria (Frequency Dependent)

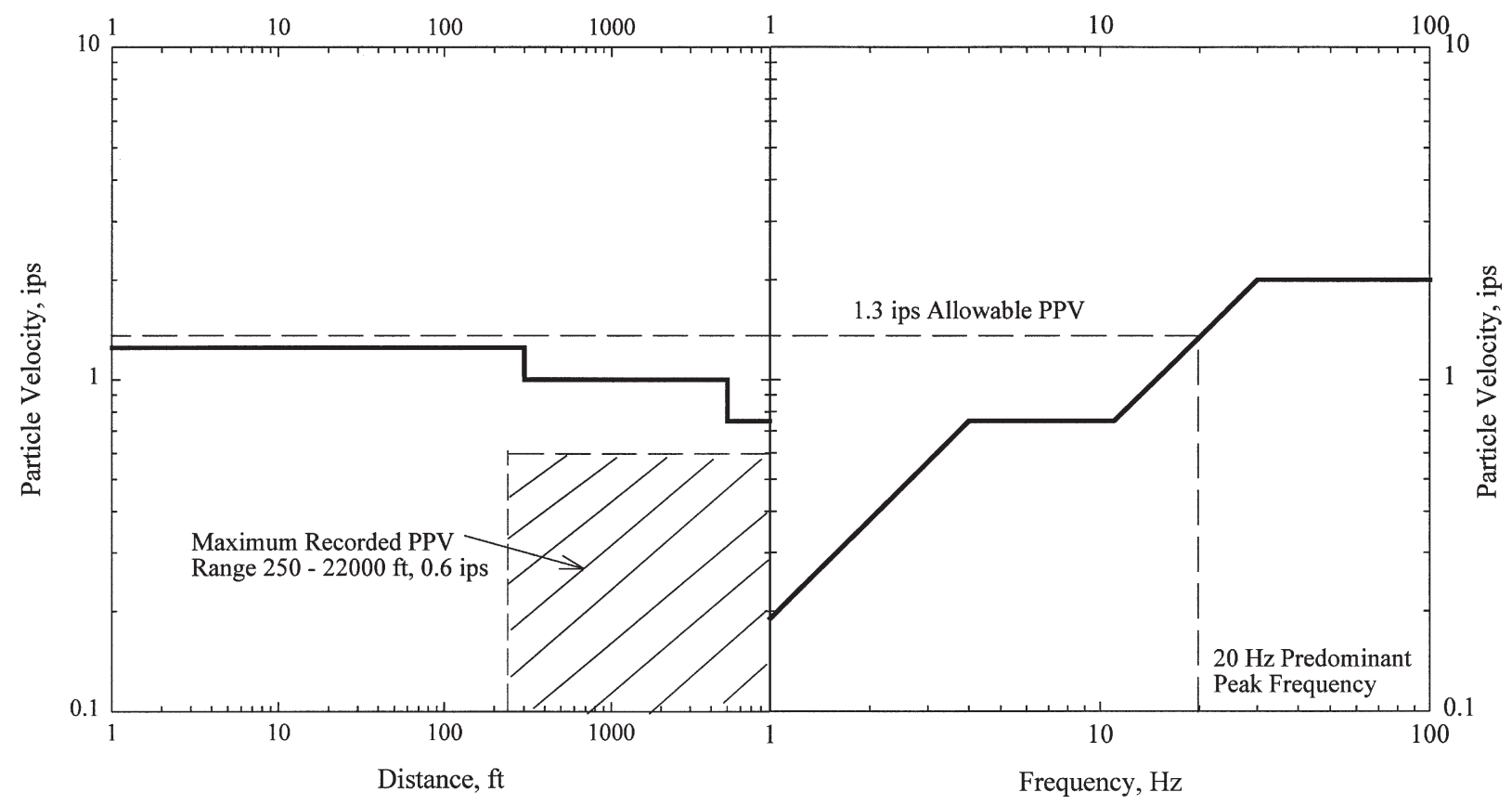

Fig. 4. Blast safety criteria used in analysis of data from the blast effects study.

are only plotted versus cubic scaling, air overpressure plots are generally not shown as a function of square scaling. The assumed mathematical model is:

$$
\mathrm{PAO}=C_{4}\left(R / W^{1 / 3}\right)^{C_{5}}
$$

Usually collection of scaled distance particle velocity data for determination of attenuation relationships will result in significant scatter about the mean line (median line for log-log relationships). Because of this scatter, most regulations require that blasts be designed on the basis of maximum probable velocities rather than average values. Many factors are responsible for the variation of particle velocities at a given scaled distance. They include variability in geological conditions, differences between types of explosives, different wave types, differences in the geometry of the explosions, as well as errors in blast timing and measurement. The same factors, with the exception of geology, are responsible for the variation of air overpressure. Since 


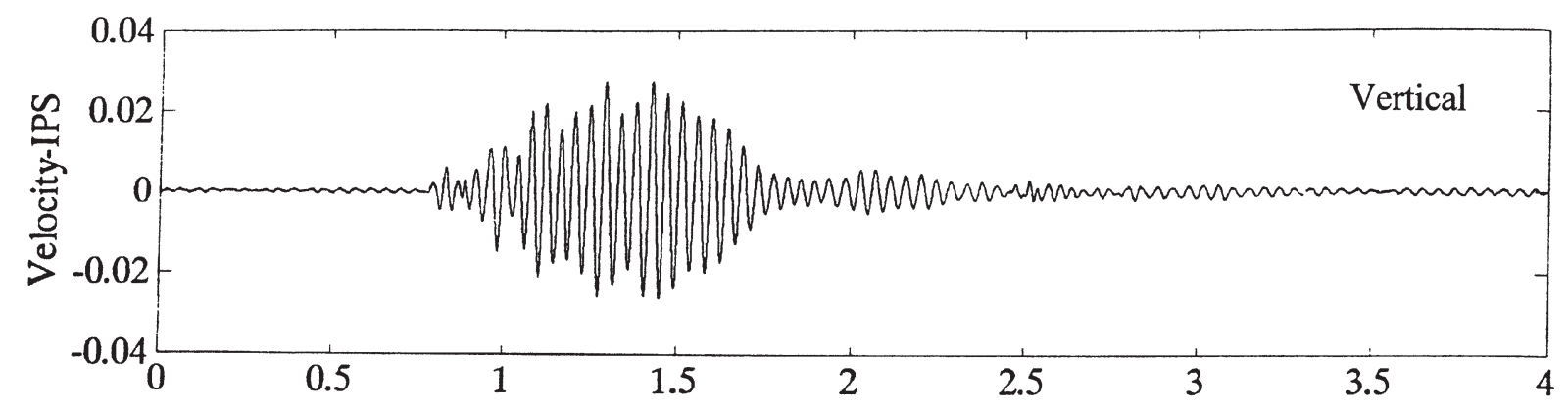

Time-Sec

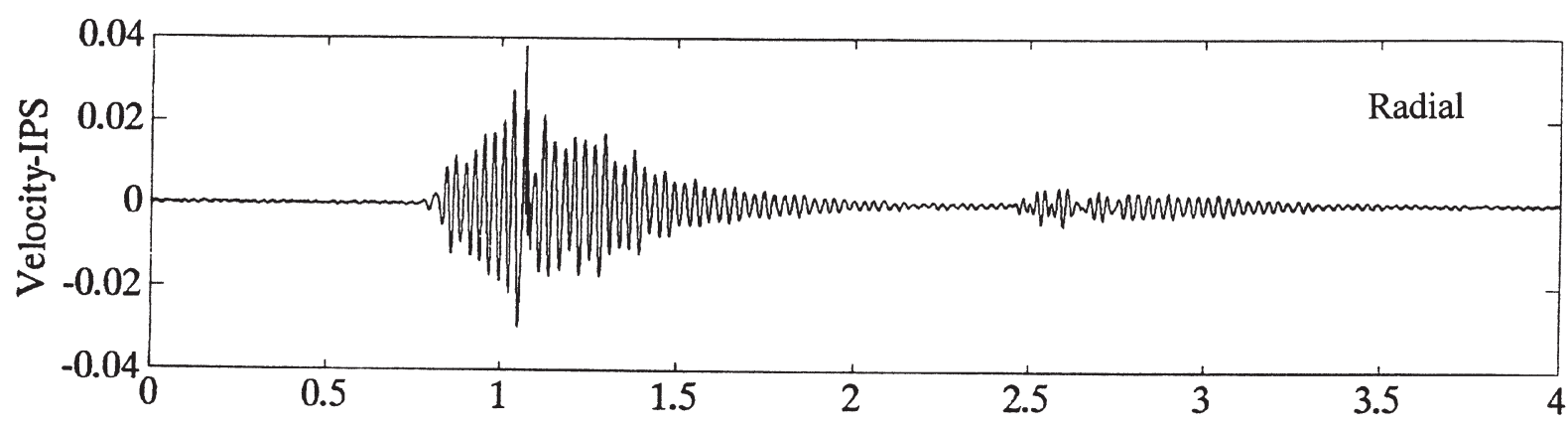

Time-Sec
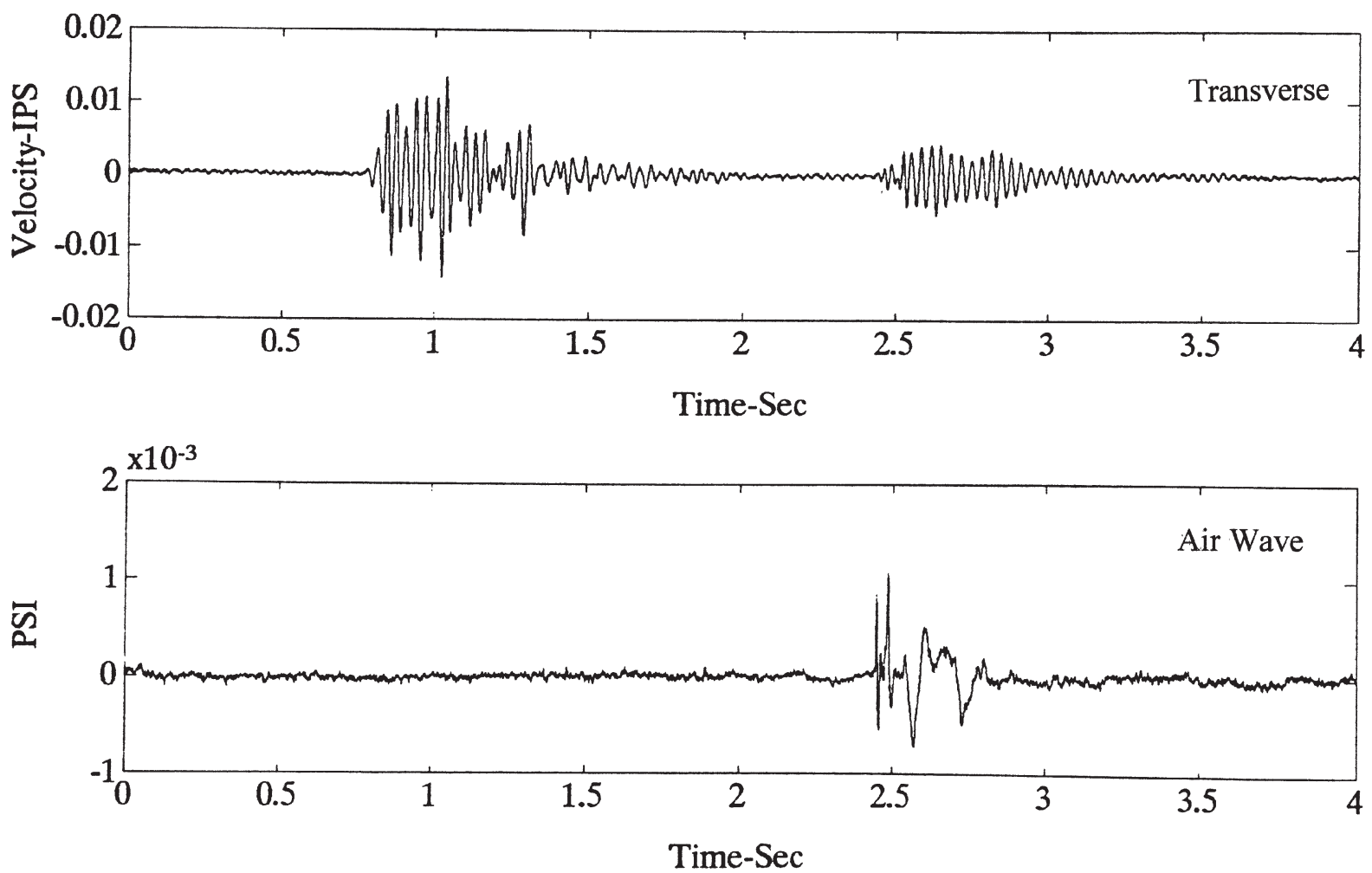

Fig. 5. Example recorded time histories showing vertical, radial, transverse and air overpressure data. 
overpressures are transmitted through air, weather conditions replace geology as a principal variable. Therefore, for the final analysis the data were also fitted with an equation representing the bound below which normally distributed fall $95 \%$ of the data.

The data were grouped and evaluated to determine a final set of equations to characterize the entire site. The average or $50 \%$ and $95 \%$ non-exceedance equations were determined from regression analysis of the $\log$ normally distributed data. These equations were determined by converting the data into logarithmic values and performing a linear regression analysis of the transformed data. From the regression analysis, the standard error of the ' $y$ ' estimate is obtained which can be used to determine the values on the $95 \%$ nonexceedance line. These values are determined by the following formula:

$$
\begin{aligned}
y_{95 \%}= & y_{50 \%} \\
& \times 1.645 \times 10^{\text {standard error of the } y \text { estimate }} .
\end{aligned}
$$

This line represents the average plus one standard deviation. The $95 \%$ non-exceedance statistical line is presented so that predictions of ground motions or air overpressures can be made with a $95 \%$ confidence that the values will not be exceeded. However, this also implies that $5 \%$ of the time the predicted values could be exceeded. Also, the $95 \%$ non-exceedance statistical line does not imply the level of exceedence, only the frequency or probability of exceedance. It can be seen in Fig. 7 that the air overpressure data exceeds the $95 \%$ line by a factor of 10 at a scaled range of $1500 \mathrm{ft}$. Therefore, when considering blast safety other empirical based curves that bound more of the data could be considered for added conservatism. One example of a very conservative prediction equation would be the empirical upper bound lines shown in Figs 6 and 7. These are constructed to bound all data and provide for no exceedances for the basis data set.

The predominant motions at the site were recorded by the vertical and radial components of the geophones. Therefore, the data recorded by the transverse component is not considered in this analysis. The vertical motions from all the data recorded at the site regardless of line direction or the day recorded were plotted together (versus both square and cubic root scaled range) to determine the $50 \%$ and $95 \%$ non-exceedance equations. The same procedure was followed for the radial and air overpressure data. Finally, the vertical and radial data were analyzed together and predictive equations determined. Results for the square root scaled distance are shown in Fig. 6. The regression analysis for this combined data produces a predictive equation based on the maximum PPV recorded at the site. Results for the air overpressure data are shown in Fig. 7.

A spectral analysis of the data was conducted so that the peak frequency associated with the various blasts could be determined. The analysis showed that the peak frequency ranges from 10 to $40 \mathrm{~Hz}$, with the predominant frequency being approximately $20 \mathrm{~Hz}$ (comparable to quarry or construction blasting). Comparing this predominate value with the criteria presented in Fig. 4, reveals that the site ground motions are well below both safe limiting criteria. Ground motions with a frequency content of $20 \mathrm{~Hz}$ have a safe threshold peak particle velocity of $1.3 \mathrm{ips}$, whereas the maximum recorded PPV at the site was 0.6 ips.

\section{Extrapolation of motions off-site}

Since all data were recorded on-site, it is necessary to perform an extrapolation of the recorded data to make an estimate of PPV and PAO levels at locations off-site. The predominant factors that would effect utilizing the equations obtained from the regression analysis for off-site predictions would be the geology, and the weather. From the discussion of the regional geology, there does not appear to be any dramatic changes in the material in which the ground motions will be traveling across the site and areas surrounding the facility. The shallow alluvial overburden and competent base rocks do not present the ususal conditions for the amplification of ground motions by thick deposits of soft soils. Also, from the recorded data there is no indication that the motions are being amplified as they travel across the site. The weather conditions at the time of blasting can have a profound effect on the resulting air overpressures. The amount of cloud cover, height of the ceiling, wind velocity, and wind direction all have a large effect on recorded motions. However, since data were recorded under a variety of weather conditions this factor should be accounted for in the predictive equations. Therefore, the following equations are presented to predict motions off-site.

Ground motion predictions:

$$
\operatorname{PPV}_{95 \%}=28.69\left(x^{-1.43}\right)
$$

PPV - velocity, ips; $x$ - scaled range, $\mathrm{ft} / \mathrm{lb}^{1 / 2}$. 
Peak Particle Velocity Regardless of Direction for NSWC

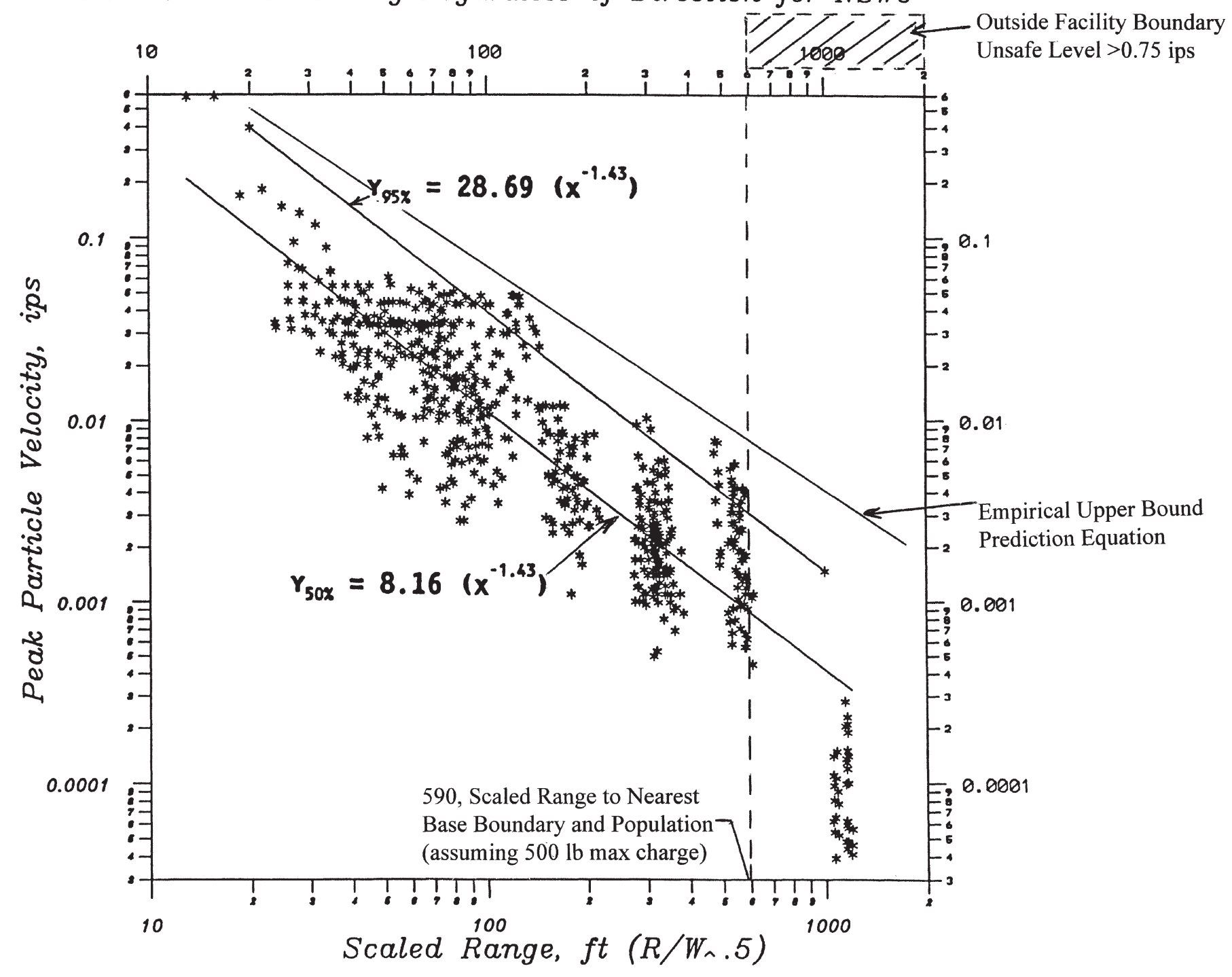

Fig. 6. Peak particle velocity versus scaled range for data collected at the site. 
All Air Overpressure Data Recorded at NSWC

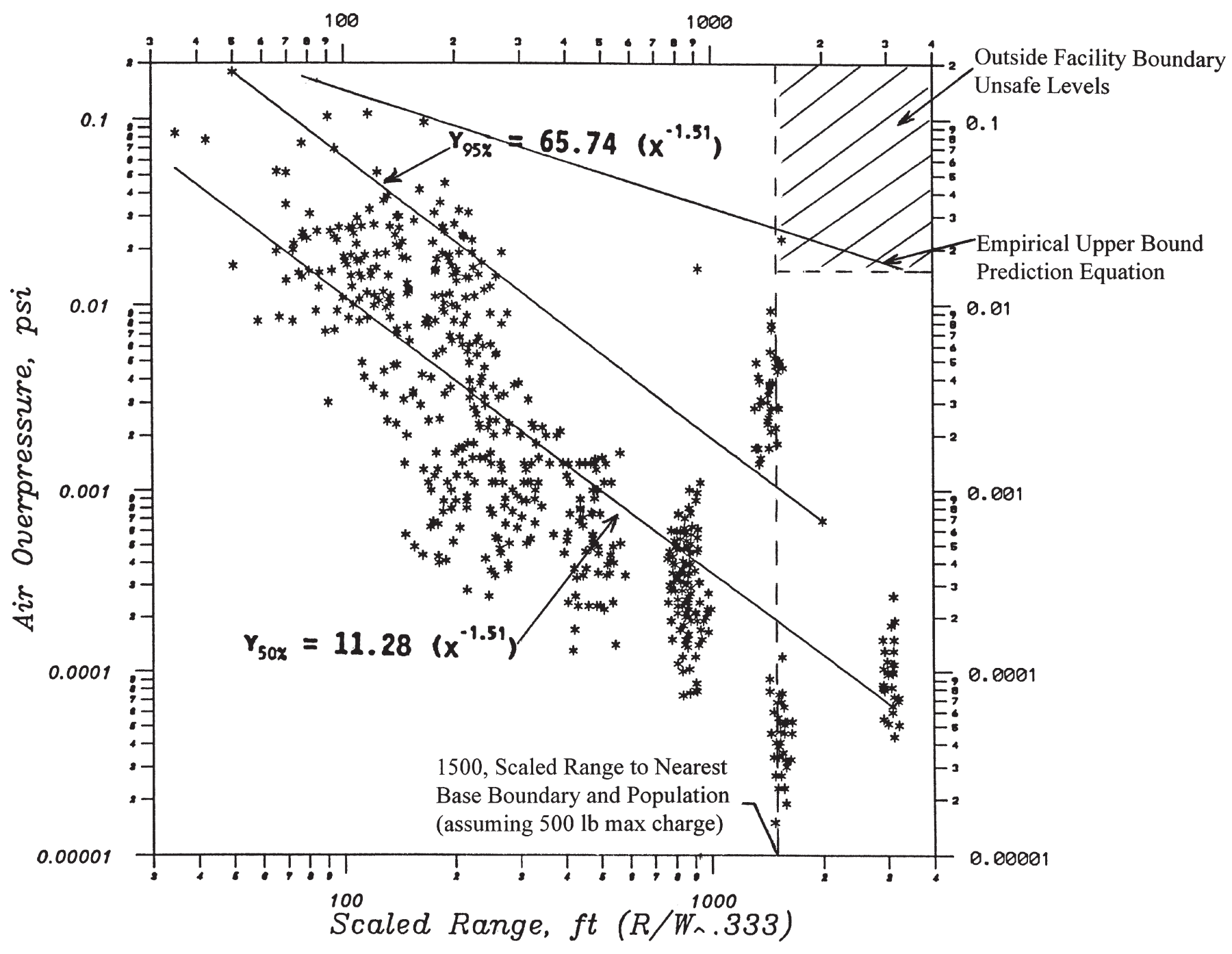

Fig. 7. Air overpressure versus scaled range for data collected at the site 
Air overpressure predictions:

$$
\mathrm{PAO}_{95 \%}=65.74\left(x^{-1.51}\right) \text {. }
$$

However, it can be seen that these prediction equations while able to estimate the most probable ground motion levels do not provide a absolute safe prediction because some recorded values exceed this by more than a factor of 10 . If the probability that the blast levels exceed the safety criteria must be very low then the attenuation curve that bounds all recorded data could be used as the most conservative equation to use to design maximum charge sizes. Using the maximum allowed explosive size $(\mathrm{NEW}=500 \mathrm{lbs}$ ) the recorded data, Figs 6 and 7, show that the probability of blast effects exceeding the criteria outside the facility boundaries are very low for the particle velocities and within the limits for air overpressures.

\section{Conclusion}

A study was completed to determine the attenuation of explosion induced ground motions and air overpressures as a function of distance from subsurface detonated charges, and to develop parameters to predict motions at distances beyond the facility boundary. A total of 210 shots were monitored producing 2048 time histories of ground motions recorded in the vertical, radial, and transverse directions, in addition to recording air overpressures. The data were analyzed for peak particle velocities and peak air overpressures, then plotted versus scaled range. A best fit line was put through the data to give average and 95\% non-exceedance predictive equations for the site and locations off-site. As a result of the analysis, Eq. (4) was developed for predicting ground motions and Eq. (5) for predicting air overpressures. In addition to the analysis as described above, the data were also compared to the alternative blasting source criteria utilizing the frequency content of the motions. This analysis also revealed that the ground motions recorded at the site and extrapolated off-site are well below the safe limiting criteria.

\section{Acknowledgement}

The work described in this paper was conducted by the U.S. Army Engineer Waterways Experiment Station. Permission was granted by the Chief of Engineers to publish this information. The view of the authors do not purport to reflect the position of the Department of the Army or the Department of Defense. This work was funded by Crane Army Ammunition Activity, Naval Surface Warfare Center, Crane, IN.

\section{References}

[1] J. Chameau, G.J. Rix and L. Empie, Measurement and analysis of civil engineering vibrations, in: Proc. 4th Int. Conf. on Case Histories in Geotechnical Engineering, St. Louis, MO. ASCE, 1998.

[2] C.H. Dowding, Blast Vibration Monitoring and Control, Prentice-Hall, Englewood Cliffs, NJ, 1985.

[3] Surface coal mining and reclamation operations; Initial and permanent regulatory programs; Use of explosives. Federal Register 30 CFR Parts 715, 780, 816, and 817, Department of the Interior, Washington, DC, 1992.

[4] Subsurface Sedimentology of the Pennsylvanian (Mansfield) Rocks; NSWC Crane, Indiana; Rockeye, Dye Burial Ground and Demolition Area Sites. Geological Survey, State of Indiana Department of Natural Resources, Bloomington, Indiana, 1992.

[5] D.E. Siskind, M.S. Stagg, J.W. Kopp and C.H. Dowding, Structure response and damage produced by ground vibration from surface mine blasting, U.S. Bureau of Mines RI 8507, 1980. 

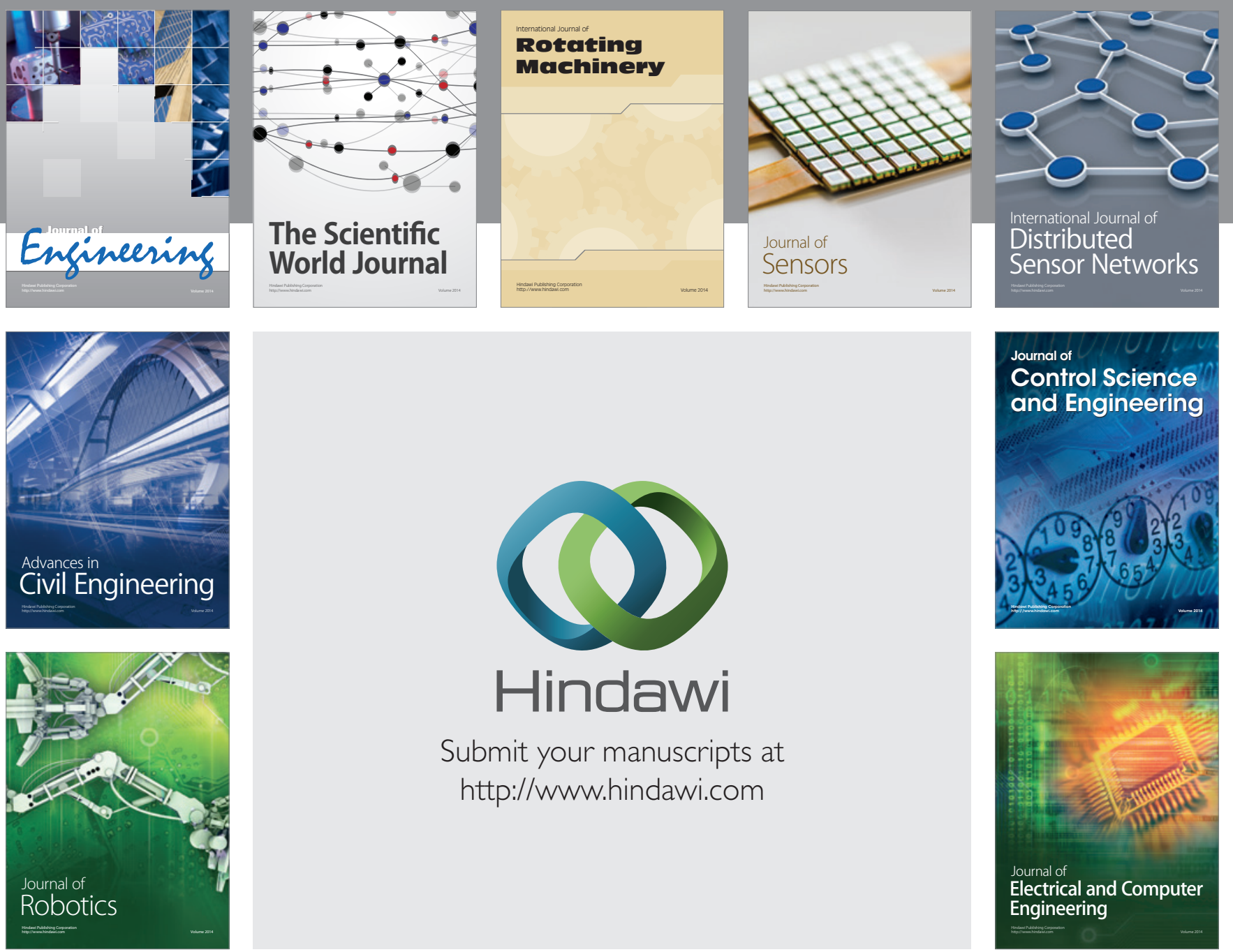

Submit your manuscripts at

http://www.hindawi.com
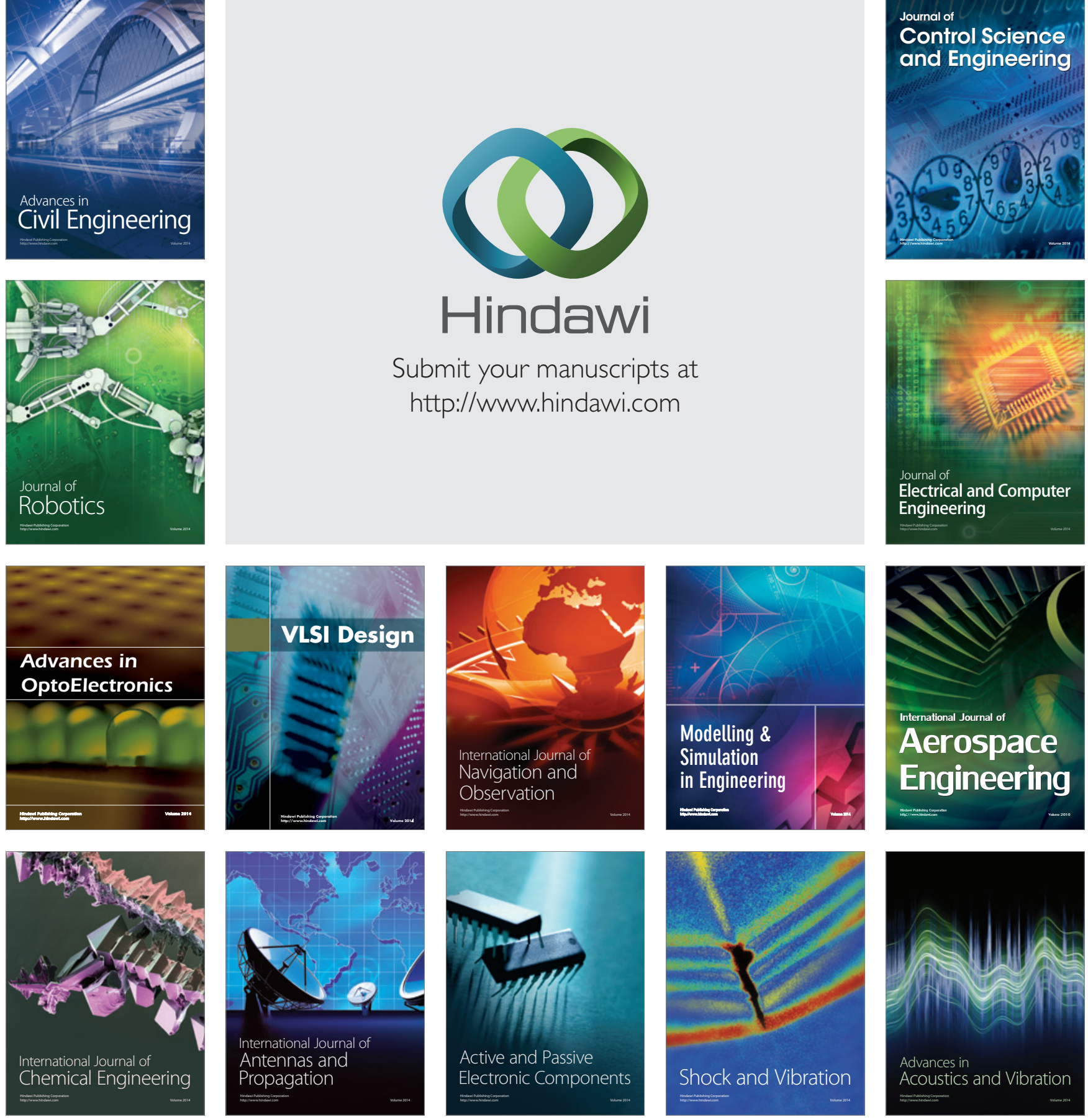